\title{
Determination of $\mathrm{Mg}$ composition in $\mathrm{Mg}_{x} \mathrm{Zn}_{1-x} \mathrm{O}$ alloy: Validity of Vegard's law
}

\author{
A. B. M. Almamun Ashrafi ${ }^{\text {a) }}$ and Yusaburo Segawa \\ Laboratory for Photophysics, RIKEN Photodynamics Research Center, 519-1399 Aoba, Sendai 980-0845, \\ Japan
}

(Received 4 November 2004; accepted 8 August 2005; published 14 September 2005)

\begin{abstract}
Vegard's law and inductively coupled plasma atomic emission spectrometry were employed to determine the $\mathrm{Mg}$ composition in $\mathrm{Mg}_{x} \mathrm{Zn}_{1-x} \mathrm{O}$ layers deposited on $6 \mathrm{H}-\mathrm{SiC}$ substrates. With the increase of $\mathrm{Mg}$ composition in $\mathrm{Mg}_{x} \mathrm{Zn}_{1-x} \mathrm{O}$ layers, the $c$-axis length decreased by 5.2048-0.072x, while the $a$-axis length increased to $3.2491+0.047 x$. The lattice constants estimated by Vegard's law and a theoretical model exhibited an uncertainty of $\sim 3 \%$ that has been attributed to the $\sim 2 \%$ lattice misfit in the $\mathrm{MgO} / \mathrm{ZnO}$ materials system. Localized exciton peaks of $\mathrm{Mg}_{x} \mathrm{Zn}_{1-x} \mathrm{O}$ alloy in photoluminescence (PL) measurements disappeared completely, while the neutral donor-acceptor pair and 1-longitudinal optical-phonon energies decreased rapidly with the increase of $\mathrm{Mg}$ composition. These PL data do not comply with Vegard's law. The asymmetric behavior in the $\mathrm{Mg}_{x} \mathrm{Zn}_{1-x} \mathrm{O}$ alloy is the subject of locally disordered $\mathrm{Mg}$ potential fluctuations and an artifact of the $c_{\mathrm{MgO}}$ and $a_{\mathrm{MgO}}$ lengths calculated theoretically. (c) 2005 American Vacuum Society.
\end{abstract}

[DOI: $10.1116 / 1.2050653$ ]

\section{INTRODUCTION}

Wide-band-gap $\mathrm{ZnO}$ has attracted attention in research as an alternative material to $\mathrm{GaN}$ for the fabrication of excitonbased laser diodes and light-emitting diodes, since it has the largest exciton and biexciton binding energies in the semiconductor material's family. ${ }^{1}$ It has been demonstrated that the exciton binding energies and band-gap energy in epitaxial $\mathrm{ZnO}$ layers can be engineered by quantum confinement and by alloying with $\mathrm{MgO}$ and $\mathrm{CdO}$ materials, respectively. ${ }^{2}$ Epitaxial $\mathrm{ZnO}$ has been alloyed with $\mathrm{MgO}$ for a $\mathrm{Mg}$ content of $40 \%$, while the band-gap energy was engineered to 4.0 $\mathrm{eV}^{2,3}$ In those studies, the $\mathrm{Mg}$ composition was determined by employing chemical techniques, such as sputtered ionmass spectroscopy, secondary ion-mass spectroscopy, and inductively coupled plasma-mass spectroscopy (ICPS). These experimental techniques are truly insensitive to the physical state of strain and bowing parameters of heterostructures. These physical parameters, in principle, play crucial roles in epitaxy and control the quality of heterostructures.

A routine determination of alloy composition by employing Vegard's law can properly account for the sample's state of strain. ${ }^{4}$ The use of Vegard's law in II-VI oxide (II-O) materials, however, requires standard $\mathrm{MgO}$ and $\mathrm{ZnO}$ lattice constants along the $a$ and $c$ axes. There has been a theoretical study of the lattice constant of wurtzite $\mathrm{MgO}$ material along the $a$ axis of $3.199 \AA$ with a $c / a$ ratio of $1.633 .^{5}$ This leads $c_{\mathrm{MgO}}$ to be $5.224 \AA$, greater than that of $c_{\mathrm{ZnO}}(5.205 \AA)$. However, with an increase of $\mathrm{Mg}$ composition in the $\mathrm{Mg}_{x} \mathrm{Zn}_{1-x} \mathrm{O}$ alloy, the $c_{\mathrm{MgZnO}}$ axis length decreases, ${ }^{2-6}$ indicating that the $c_{\mathrm{MgO}}$ has to be less than the $c_{\mathrm{ZnO}}\left(c_{\mathrm{MgO}}\right.$

${ }^{a)}$ Electronic mail: ashrafi@ riken.jp
$\left.<c_{\mathrm{ZnO}}\right)$. Therefore, the theoretical calculation may need to be reconsidered for the exact values of the $c / a$ ratio and the lattice constant of the $\mathrm{MgO}$ material.

In this article, $c_{\mathrm{MgO}}$ and $a_{\mathrm{MgO}}$ lengths have been assigned to $5.086 \AA$ and $3.199 \AA$, respectively, that have been presented in Table I. Using Vegard's law, the Mg composition in $\mathrm{Mg}_{x} \mathrm{Zn}_{1-x} \mathrm{O}$ alloys has been estimated to be from 0 to $56 \%$, which is consistent with results of other studies. The lattice constants in $\mathrm{Mg}_{x} \mathrm{Zn}_{1-x} \mathrm{O}$ alloys as a function of $\mathrm{Mg}$ composition determined by employing Vegard's law and a theoretical model showed an error limit of $\sim 3 \%$. The photon energies of $\mathrm{Mg}_{x} \mathrm{Zn}_{1-x} \mathrm{O}$ alloys do not follow Vegard's law and the localized exciton $\left(D^{0} X\right)$ disappeared completely in the photoluminescence (PL) spectra, while the neutral donoracceptor pair $\left(A^{0} X\right)$ and 1-longitudinal optical (LO)-phonon bands energies decreased rapidly with increasing $\mathrm{Mg}$ content. These asymmetric behaviors in the $\mathrm{Mg}_{x} \mathrm{Zn}_{1-x} \mathrm{O}$ alloys are the subject of locally disordered $\mathrm{Mg}$ fluctuations and an artifact of the $c_{\mathrm{MgO}}$ and $a_{\mathrm{MgO}}$ lengths calculated theoretically.

\section{EXPERIMENT}

$\mathrm{Mg}_{x} \mathrm{Zn}_{1-x} \mathrm{O}$ alloys were grown directly on $6 \mathrm{H}-\mathrm{SiC}(0001)$ substrates by metalorganic chemical-vapor deposition. The substrate cleaning and processing have been described in detail elsewhere. ${ }^{7,8}$ For the growth of $\mathrm{Mg}_{x} \mathrm{Zn}_{1-x} \mathrm{O}$ layers, the flow rates of diethyl zinc (DEZn) and bismethyl cyclopentadienyl-magnesium $\left[(\mathrm{MeCp})_{2} \mathrm{Mg}\right]$ were controlled by adjusting the flow rate of the carrier gas $\mathrm{N}_{2}$. The substrate temperature was then increased to the selected temperature of $475{ }^{\circ} \mathrm{C}$ for the successive growth of $\mathrm{Mg}_{x} \mathrm{Zn}_{1-x} \mathrm{O}$ layers. DEZn and $(\mathrm{MeCp})_{2} \mathrm{Mg}$ were allowed to flow first for $\sim 20 \mathrm{~s}$, and then $\mathrm{O}_{2}$ was introduced. In these $\mathrm{Mg}_{x} \mathrm{Zn}_{1-x} \mathrm{O}$ alloys, the flow rates of $(\mathrm{MeCp})_{2} \mathrm{Mg}$ and $\mathrm{O}_{2}$ were kept constant at 20 
TABLE I. Physical properties of the common II-O compound semiconductors reported experimentally and/or theoretically.

\begin{tabular}{cccc}
\hline \hline Parameters & $\mathrm{MgO}^{\mathrm{a}}$ & $\mathrm{ZnO}^{\mathrm{b}}$ & $\mathrm{CdO}^{\mathrm{c}}$ \\
\hline$a(\AA)$ & 3.199 & 3.250 & 3.660 \\
$c(\AA)$ & 5.086 & 5.205 & 5.589 \\
$\mathrm{C}_{11}(\mathrm{GPa})$ & 298 & 207 & $\cdots$ \\
$\mathrm{C}_{12}(\mathrm{GPa})$ & 96 & 117 & $\cdots$ \\
$\mathrm{C}_{44}(\mathrm{GPa})$ & 42.5 & 148 & $\cdots$ \\
\hline
\end{tabular}

${ }^{\mathrm{a}}$ See Refs. 5 and 9-11.

${ }^{\mathrm{b}}$ See Ref. 2.

${ }^{\mathrm{c}}$ See Ref. 12

and $10 \mathrm{sccm}$, respectively, while the flow rate of DEZn was varied from 0 to $12 \mathrm{sccm}$. The typical $\mathrm{Mg}_{x} \mathrm{Zn}_{1-x} \mathrm{O}$ layer thickness was $0.5 \mu \mathrm{m}$.

For determination of the $\mathrm{Zn}$ and $\mathrm{Mg}$ contents, $\mathrm{MgZnO}$ samples were dissolved in concentrated $\mathrm{HNO}_{3}$ followed by ICPS analysis. The ICPS system is considered a sequential multielement analyzer that has scan times less than $20 \mathrm{~ms}$ for one sweep. The signal intensity is a function of the number of analytic ions in the plasma and the mass-dependent transport through the mass spectrometer. Determination of $\mathrm{Zn}$ and Mg was performed with a Shimadzu ICPS-1000IV spectrophotometer.

\section{RESULTS AND DISCUSSION}

To justify the study of the $\mathrm{Mg}_{x} \mathrm{Zn}_{1-x} \mathrm{O}$ alloy, an overview of epitaxial $\mathrm{ZnO}$ layers deposited on $6 \mathrm{H}-\mathrm{SiC}$ substrates is briefly discussed. ${ }^{7}$ The $\mathrm{ZnO}$ layers exhibited virtually relaxed lattice constants along the $a$ and $c$ axes of 3.246 and $5.205 \AA$, respectively. With these lattice constants, the dominant $D^{0} X$ was recorded to be $3.364 \mathrm{eV}$ at $4 \mathrm{~K}$.

Figure 1 shows the X-ray diffraction (XRD) patterns obtained from $\mathrm{Mg}_{x} \mathrm{Zn}_{1-x} \mathrm{O}$ layers deposited on $6 \mathrm{H}-\mathrm{SiC}$ substrates. It is noted that all of the $\mathrm{Mg}_{x} \mathrm{Zn}_{1-x} \mathrm{O}$ layers orient along the (002) and (205) planes, which correspond to sym-

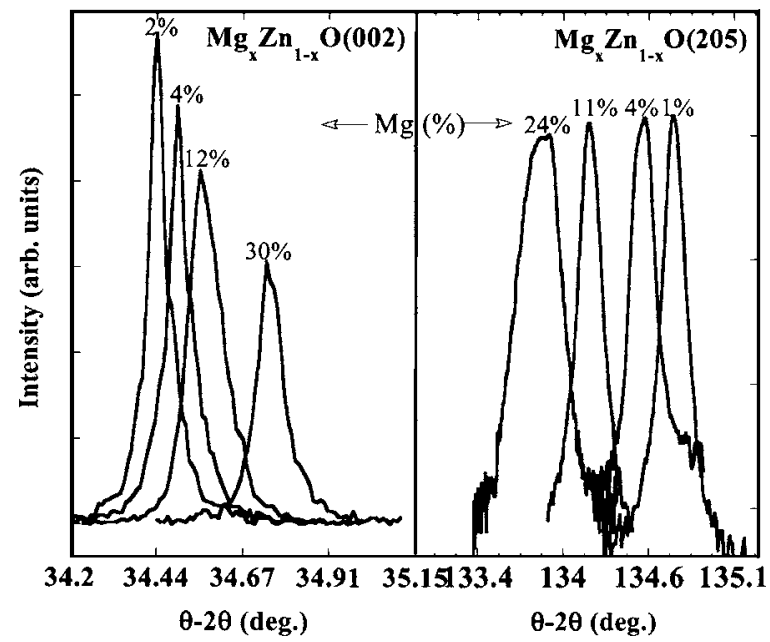

FIG. 1. XRD peaks of $\mathrm{Mg}_{x} \mathrm{Zn}_{1-x} \mathrm{O}$ layers along the (002) and (205) planes. The XRD peak positions are shifted with the increasing $\mathrm{Mg}$ composition. The typical $\mathrm{MgZnO}$ layer thickness was $0.5 \mu \mathrm{m}$.

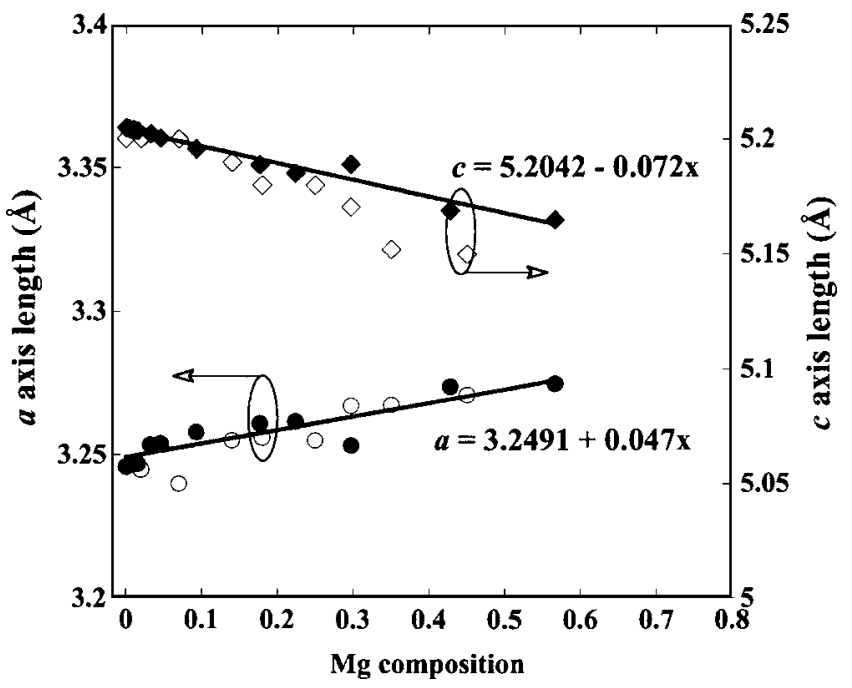

FIG. 2. $c_{\mathrm{MgZnO}}$-axis and $a_{\mathrm{MgZnO}}$-axis lengths as a function of $\mathrm{Mg}$ compositions are plotted determined by employing the Vegard's law as $\mathrm{Mg}_{x} \mathrm{Zn}_{1-x} \mathrm{O}=x \mathrm{MgO}+(1-x) \mathrm{ZnO}$ using the lattice constants calculated from the XRD spectra. The filled and open symbols are experimental data from these experiments and cited from Ref. 3, respectively.

metric and asymmetric peaks. It is evident that these XRD peaks shift systematically: The (002) peak positions shifted to higher angles, while the (205) peak positions shifted to lower angles with increasing $\mathrm{Mg}$ content. The out-of-plane lattice constant of the $\mathrm{Mg}_{x} \mathrm{Zn}_{1-x} \mathrm{O}$ layers was calculated using Bragg's law for the (002) plane by $n \lambda=2 d \sin \theta$, where, $\lambda$ and $d$ are the $\mathrm{x}$-ray wavelength and the diffracted lattice constant of the epitaxial layers, respectively. However, for the asymmetric (205) planes of $\mathrm{Mg}_{x} \mathrm{Zn}_{1-x} \mathrm{O}$ alloys with the first-order approximation $(n=1)$, Bragg's law can be written as

$$
\sin \theta=\frac{\lambda}{2} \sqrt{\frac{16}{3 a^{2}}+\frac{25}{c^{2}}}
$$

Using Eq. (1), the $a_{\mathrm{MgZnO}}$ lengths were estimated for the relative $c$-axis lengths calculated from the (002) planes.

A systematic study of the $c_{\mathrm{MgZnO}}$ and $a_{\mathrm{MgZnO}}$ lengths as a function of $\mathrm{Mg}$ composition were determined and plotted in Fig. 2. For the comparative studies, the $\mathrm{Mg}_{x} \mathrm{Zn}_{1-x} \mathrm{O} / \mathrm{Al}_{2} \mathrm{O}_{3}$ film parameters are plotted together with the $\mathrm{Mg}_{x} \mathrm{Zn}_{1-x} \mathrm{O} / 6 \mathrm{H}-\mathrm{SiC}$ heterostructure, cited from Ref. 3. The $c$-axis length decreases, while the $a$-axis length increases with the increase of $\mathrm{Mg}$ composition in $\mathrm{Mg}_{x} \mathrm{Zn}_{1-x} \mathrm{O}$ layers grown on $6 \mathrm{H}-\mathrm{SiC}$ and $\mathrm{Al}_{2} \mathrm{O}_{3}$ substrates. It is clear that the $c_{\mathrm{MgZnO}}$ and $a_{\mathrm{MgZnO}}$ lengths are consistent in these heterostructures for composition where the $\mathrm{Mg}$ content is $<30 \%$. For the $\mathrm{Mg}_{x} \mathrm{Zn}_{1-x} \mathrm{O} / 6 \mathrm{H}-\mathrm{SiC}$ heterostructure, however the fitted results of $c$-axis and $a$-axis lengths are found to be $5.2042-0.072 x$ and $3.2491+0.047 x$, respectively. It reveals that the $c$-axis length decreases 1.5 times faster than the $a$-axis length, i.e., the $c$-axis length of $\mathrm{Mg}_{x} \mathrm{Zn}_{1-x} \mathrm{O}$ alloys shrinks rapidly, and agrees well with the known fact that the $c_{\mathrm{MgO}}$-axis length should be less than that of the $c_{\mathrm{ZnO}}$. 

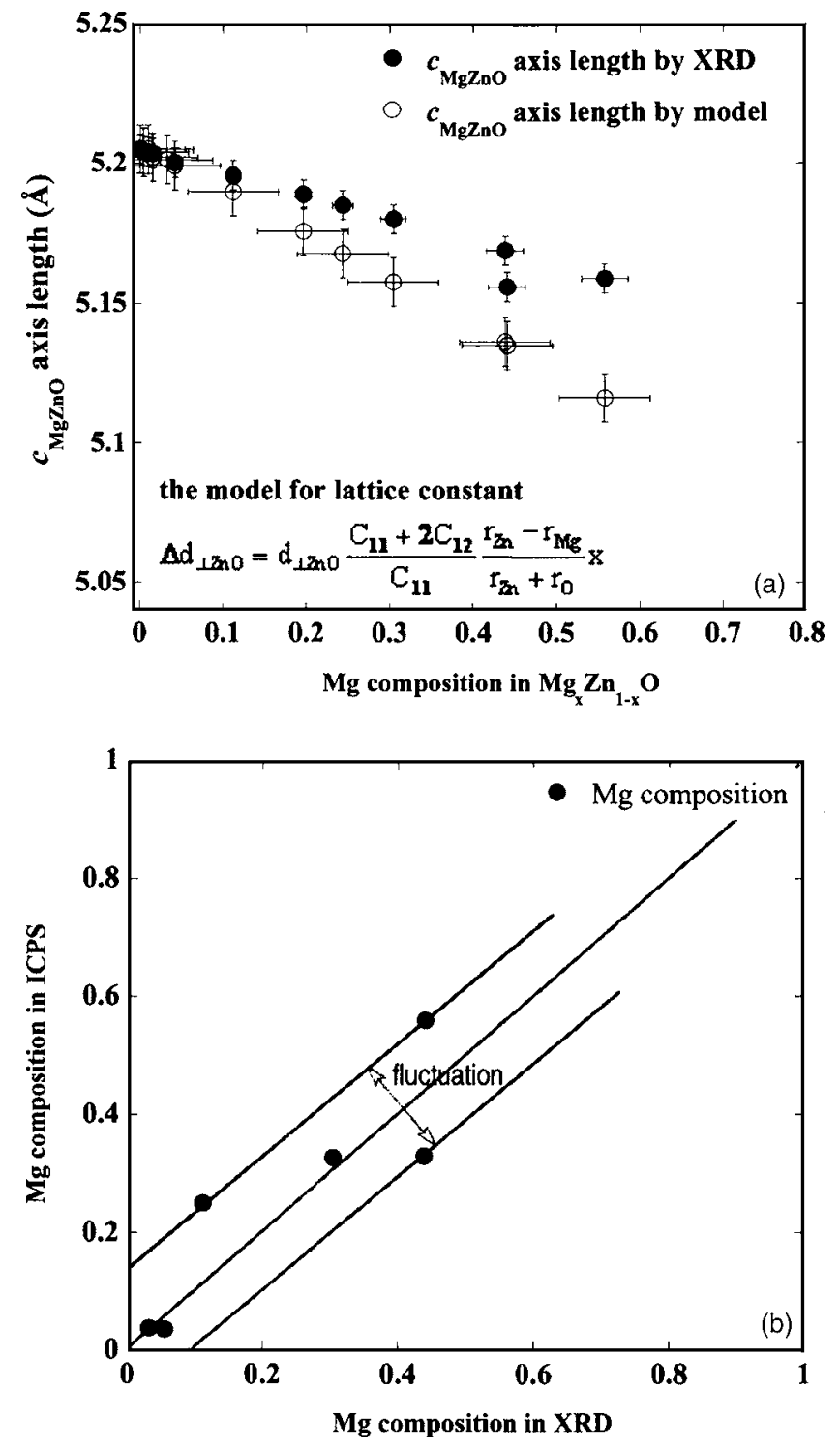

FIG. 3. (a) $c_{\mathrm{MgZnO}}-$ axis lengths obtained by Vegard's law and from the theoretical model calculation as a function of $\mathrm{Mg}$ contents and (b) $\mathrm{Mg}$ composition estimated by the ICPS and XRD are plotted. The physical parameters used in these calculations are represented in Table I.

The accuracy of $\mathrm{Mg}$ composition determination using Bragg's and Vegard's laws can be verified by using the theoretical model calculation. For an ideal $\mathrm{ZnO}$ crystal, the distance $\left(R_{\mathrm{Zn}-\mathrm{O}}\right)$ between two neighboring $\mathrm{Zn}$ and $\mathrm{O}$ atoms can be written as $R_{\mathrm{Zn}-\mathrm{O}}=r_{\mathrm{Zn}}+r_{\mathrm{O}}$, where $r_{\mathrm{Zn}}(0.60 \AA)$ and $r_{\mathrm{O}}(1.38$ $\AA$ ) are Pauli covalent radii of $\mathrm{Zn}$ and $\mathrm{O}$ atoms, respectively. Assuming a variation in $R_{\mathrm{Zn}-\mathrm{O}}$ due to the kinetics of neighboring atoms, the elastic strain $\varepsilon_{\mathrm{es}}$ in the $\langle 0001\rangle$ direction will be $\varepsilon_{\mathrm{es}}=\Delta R_{\mathrm{Zn}-\mathrm{O}} / R_{\mathrm{Zn}-\mathrm{O}}$.

For an ideal $\mathrm{MgZnO}$ solid solution, in principle, a $\mathrm{Mg}$ $\left(r_{\mathrm{Mg}}=0.57 \AA\right)$ atom occupies a substitutional $\mathrm{Zn}$ site. Therefore, the strain $\varepsilon_{\mathrm{es}}$ in the $\langle 0001\rangle$ direction due to $\mathrm{Mg}$ atom incorporation becomes $\boldsymbol{\varepsilon}_{\mathrm{es}}=\Delta R_{\mathrm{Zn}-\mathrm{O}} / R_{\mathrm{Zn}-\mathrm{O}}=\left\{\left(r_{\mathrm{Zn}}-r_{\mathrm{Mg}}\right) /\left(r_{\mathrm{Zn}}\right.\right.$ $\left.\left.+r_{\mathrm{O}}\right)\right\} x$ where $x$ is the $\mathrm{Mg}$ composition in $\mathrm{Mg}_{x} \mathrm{Zn}_{1-x} \mathrm{O}$ alloy. Hence, the lattice constant variation due to $\mathrm{Mg}$ atom incorporation into the $\mathrm{Mg}_{x} \mathrm{Zn}_{1-x} \mathrm{O}$ layers can be written as

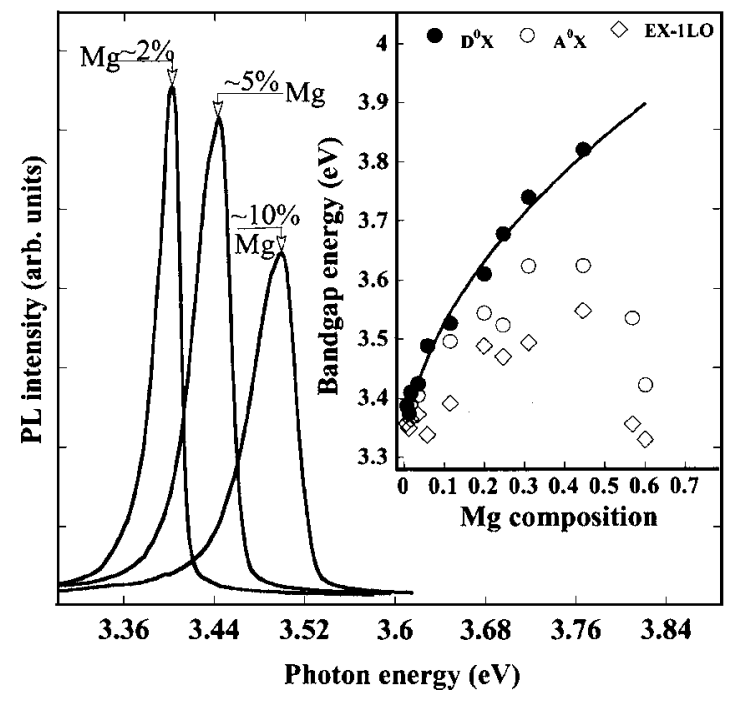

FIG. 4. Selective PL spectra of $\mathrm{Mg}_{x} \mathrm{Zn}_{1-x} \mathrm{O}$ layers grown on $6 \mathrm{H}-\mathrm{SiC}$ substrates. The inset shows the Mg composition-dependent PL peak energy positions. The Mg composition is determined by using Vegard's law. The $D^{0} X$ band energy increases, while the $A^{0} X$ and FX-1LO decreases with the increase of $\mathrm{Mg}$ composition typically for $x>30 \%$.

$$
\Delta d_{\perp \mathrm{ZnO}}=d_{\perp \mathrm{ZnO}} \frac{C_{11}+2 C_{12}}{C_{11}} \frac{r_{\mathrm{Zn}}-r_{\mathrm{Mg}}}{r_{\mathrm{Zn}}+r_{\mathrm{O}}} x,
$$

where $C_{11}$ and $C_{12}$ are the elastic stiffness constants plotted in Table I.

Figure 3(a) shows the calculated dependence $(\bigcirc)$ of $c_{\mathrm{MgZnO}}$ axis length in $\mathrm{Mg}_{\mathrm{x}} \mathrm{Zn}_{1-\mathrm{x}} \mathrm{O}$ alloys as a function of $\mathrm{Mg}$ composition using the simplified model [Eq. (2)] together with the XRD data. The physical parameters used in these calculations are plotted in Table I. The model calculation indicated that the $c_{\mathrm{MgZnO}}$-axis length decreases monotonically, while the $c_{\mathrm{MgZnO}}$-axis length is almost linear with the increase of $\mathrm{Mg}$ composition when estimated by Vegard's law. The maximum error in lattice constants calculated from the simplified model (2) and Vegard's law is $\sim 3 \%$. This uncertainty has been attributed to the large lattice misfit in the $\mathrm{ZnO} / \mathrm{MgO}$ materials system of $\sim 2 \%{ }^{13}$ Neugebauer et al. ${ }^{9}$ reported that the atomic relaxation in such a large lattice mismatch material system is of great significance to the lattice property. This suggests that the $\sim 3 \%$ discrepancy between this simplified model and Vegard's law comes from the atomic relaxation.

The $\mathrm{Mg}$ compositions in $\mathrm{Mg}_{x} \mathrm{Zn}_{1-x} \mathrm{O} / 6 \mathrm{H}-\mathrm{SiC}$ heterostructures were also determined experimentally by ICPS, which are almost consistent with the Vegard's law plotted in Fig. 3(b). The fluctuation of Mg content is marked between the Vegard's law and ICPS experimental results. This fluctuation may be contributed due to the theoretically calculated $c_{\mathrm{MgO}}$-axis length based on the $c / a$ approximation of 1.59 and/or $\mathrm{Mg}$ incorporation in interstitial or antisites of the $\mathrm{ZnO}$ lattices.

Figure 4 shows selective $\mathrm{Mg}$ composition-dependent PL spectra dominated by $D^{0} X$, neutral donor-acceptor pair $\left(A^{0} X\right)$, and 1LO-phonon bands. The details of the PL prop- 
erties will be reported elsewhere. With the increase in $\mathrm{Mg}$ content from 0 to $40 \%$ that has been determined by employing Vegard's law, the $D^{0} X$ band energy is blueshifted by $\sim 0.6 \mathrm{eV}$. The systematic $\mathrm{Mg}$ composition-dependent band energies of $\mathrm{Mg}_{x} \mathrm{Zn}_{1-x} \mathrm{O}$ layers are plotted in the inset of Fig. 4. The $D^{0} X, A^{0} X$, and 1LO-phonon energies increase slowly with the increasing $\mathrm{Mg}$ composition for $x<30 \%$. However, for the higher $\mathrm{Mg}$ composition $(x>30 \%)$, the $D^{0} X$ peak disappeared in the PL spectra, while the $A^{0} X$ and 1LOphonon bands energies decrease rapidly. We attempted to fit these PL data but these do not follow the Vegard's law. These nonlinear and asymmetric behaviors for $D^{0} X, A^{0} X$, and 1LOphonon require further studies for clarification.

While the PL properties do not satisfy Vegard's law, the structural properties comply with both Bragg's and Vegard's laws. However, the transmission and reflectance measurements, together with the PL, can give insight into the details of these optical properties. Critical investigations of these properties in $\mathrm{Mg}_{x} \mathrm{Zn}_{1-x} \mathrm{O}$ layers are under way, and the studies will be reported elsewhere. However, it is expected that the inhomogeneous $\mathrm{Mg}$ incorporation microscopically in $\mathrm{Mg}_{x} \mathrm{Zn}_{1-x} \mathrm{O}$ layers may have an active role that has made a contradiction between the structural and optical properties, although a rather homogeneous alloying is expected due to the similar tetrahedral ionic radius of $\mathrm{Mg}^{2+}$ and $\mathrm{Zn}^{2+}$ to 0.57 and $0.60 \AA$, respectively. ${ }^{2-11}$

\section{CONCLUSION}

Ternary $\mathrm{Mg}_{x} \mathrm{Zn}_{1-x} \mathrm{O}$ material has been deposited on $6 \mathrm{H}-$ $\mathrm{SiC}$ substrates for the $\mathrm{Mg}$ composition of $0-56 \%$. The $\mathrm{Mg}$ compositions determined by ICPS and Vegard's law fluctuated for 5-8\%, while the $c_{\mathrm{MgZnO}}$ length estimated by Vegard's law and ICPS showed an uncertainty of $\sim 3 \%$. It was found that the $c_{\mathrm{MgZnO}}$-axis length decreases 1.5 times faster than does the $a_{\mathrm{MgZnO}^{-}}$-axis length. It was also found that the photon energies of the $\mathrm{Mg}_{x} \mathrm{Zn}_{1-x} \mathrm{O}$ alloy do not comply with Vegard's law. Although the structural properties of $\mathrm{Mg}_{x} \mathrm{Zn}_{1-x} \mathrm{O}$ alloy follow Vegard's law, no clear conclusion was found for optical properties for validity of Vegard's law.

\section{ACKNOWLEDGMENT}

This work was supported in part by the Special Postdoctoral Research Fellowship Program, Photodynamics Research Center, The Institute of Physical and Chemical Research (RIKEN), Japan.

${ }^{1}$ T. Makino, K. Tamura, C. H. Chia, Y. Segawa, M. Kawasaki, A. Ohtomo, and H. Koinuma, Phys. Rev. B 65, 121201 (2002); M. Zamfirescu, A. Kavokin, B. Gil, G. Malpuech, and M. Kaliteevski, ibid. 65, 161205 (2002).

${ }^{2}$ T. Makino, Y. Segawa, M. Kawasaki, A. Ohtomo, R. Shiroki, K. Tamura, T. Yasuda, and H. Koinuma, Appl. Phys. Lett. 78, 1237 (2001).

${ }^{3}$ A. Ohtomo, M. Kawasaki, T. Koida, K. Masubuchi, H. Koinuma, Y. Sakurai, Y. Yoshida, T. Yasuda, and Y. Segawa, Appl. Phys. Lett. 72, 2466 (1998).

${ }^{4}$ S. W. Wang, S. F. Woon, W. J. Fan, W. K. Loke, T. K. Ng, and S. Z. Wang, J. Appl. Phys. 96, 2010 (2004).

${ }^{5}$ S. Limpijumnong and W. R. Lambrecht, Phys. Rev. B 63, 104103 (2001).

${ }^{6}$ W. I. Park, G.-C. Yi, and H. M. Jang, Appl. Phys. Lett. 79, 2022 (2001).

${ }^{7}$ A. B. M. A. Ashrafi, B.-P. Zhang, N. T. Binh, K. Wakatsuki, and Y. Segawa, Jpn. J. Appl. Phys., Part 1 43, 1114 (2004).

${ }^{8}$ A. B. M. A. Ashrafi, N. T. Binh, B.-P. Zhang, and Y. Segawa, Appl. Phys. Lett. 84, 2814 (2004); A. B. M. A. Ashrafi and Y. Segawa, Appl. Surf. Sci. 249, 139 (2005)

${ }^{9}$ J. Neugebaur and C. G. Walle, Phys. Rev. B 51, 10568 (1995).

${ }^{10}$ Y. Matsumoto, M. Murakami, Z. Jin, A. Ohtomo, M. Lippmann, M. Kawasaki, and H. Koinuma, Jpn. J. Appl. Phys., Part 2 38, L603 (1999).

${ }^{11}$ S. V. Sinogeikin and J. D. Bass, Phys. Rev. B 59, R14141 (1999).

${ }^{12}$ R. J. G. Moreno and N. Takeuchi, Phys. Rev. B 66, 205205 (2002).

${ }^{13}$ S. G. Lee and K. J. Chang, Phys. Rev. B 52, 1918 (1995). 